(1)

CrossMark

\title{
Chronic breathlessness: re-thinking the symptom
}

\author{
To the Editor:
}

We agree with much presented by Mcnaughton et al. [1] in their response to our proposed chronic breathlessness syndrome, and appreciate their supportive comments [2]. In particular, we agree that patients and their carers must be at the centre of the next steps, as we stated, "Importantly, the involvement of patients and family caregivers in the development of consensus can now be addressed given the frame which this initial work provides" [2].

However, they state concerns that delineation as a syndrome would cause "further medicalisation of breathlessness" and "drive people with breathlessness further underground". We are unaware of any evidence to indicate that delineation of a syndrome will reduce patients' ability or willingness to discuss this symptom with their clinicians. Rather, the converse appears to be the case. For example, we now have better recognition and management of delirium, sepsis and heart failure: all clinical syndromes of previously neglected clinical presentations. Clinical practice operates on a system of patterns and frameworks, and whilst we await the views of patients and carers with interest, we hope that designation as a clinical syndrome will encourage clinicians to initiate routine enquiry with their patients about whether they are living with chronic breathlessness and, if so, how it impacts on their lives, in order to provide evidence-based management. In clinical practice and research, patients living with chronic breathlessness welcome a symptom-targeted enquiry $[3,4]$. It is difficult to see how, by encouraging clinicians to actively identify and respond to chronic breathlessness, this could drive the symptom "further underground".

Miriam J. Johnson ${ }^{1}$, Janelle Yorke ${ }^{2}$, John Hansen-Flaschen $\oplus^{3}$, Magnus Ekström ${ }^{4}$ and David C. Currow ${ }^{1,5}$

${ }^{1}$ Wolfson Palliative Care Research Centre, Hull York Medical School, University of Hull, Hull, UK. ${ }^{2}$ School of Nursing, Midwifery and Social Work, University of Manchester, Manchester, UK. ${ }^{3}$ Perelman School of Medicine, Hospital of the University of Pennsylvania, Philadelphia, PA, USA. ${ }^{4}$ Dept of Clinical Sciences, Division of Respiratory Medicine and Allergology, Lund University, Lund, Sweden. ${ }^{5}$ Faculty of Health, University of Technology Sydney, Sydney, Australia.

Correspondence: Miriam J. Johnson, Allam Medical Building, Hull York Medical School, University of Hull, Hull, HU6 7RX, UK. Email: miriam.johnson@hyms.ac.uk

@ERSpublications

Chronic breathlessness: designation as a clinical syndrome to encourage clinicians to ask patients routinely if they are living with this neglected and often invisible symptom and, if so, how it impacts on their lives http://ow.ly/QqtY30iWKSb

Cite this article as: Johnson MJ, Yorke J, Hansen-Flaschen J, et al. Chronic breathlessness: re-thinking the symptom. Eur Respir J 2018; 51: 1800340 [https://doi.org/10.1183/13993003.00340-2018].

Received: Feb 152018 | Accepted: Feb 162018

Conflict of interest: D.C. Currow is an unpaid advisory board member for Helsinn Pharmaceuticals; a paid consultant and receives payment for intellectual property with Mayne Pharma; and is a consultant with Specialist Therapeutics Australia Pty. Ltd.

\section{References}

1 Macnaughton J, Oxley R, Rose A, et al. Chronic breathlessness: re-thinking the symptom. Eur Respir J 2018; 51: 1702331.

2 Johnson MJ, Yorke J, Hansen-Flaschen J, et al. Towards an expert consensus to delineate a clinical syndrome of chronic breathlessness. Eur Respir J 2017; 49: 1602277.

3 Johnson MJ, Booth S, Currow DC, et al. A mixed-methods, randomized, controlled feasibility trial to inform the design of a phase III trial to test the effect of the handheld fan on physical activity and carer anxiety in patients with refractory breathlessness. J Pain Symptom Manage 2016; 51: 807-815.

4 Clark AL, Johnson MJ, Fairhurst C, et al. Long term oxygen therapy for quality of life for people with chronic heart failure: a pragmatic, mixed-methods randomized controlled trial. Health Technology Assessment 2015; 19: 1-148. 